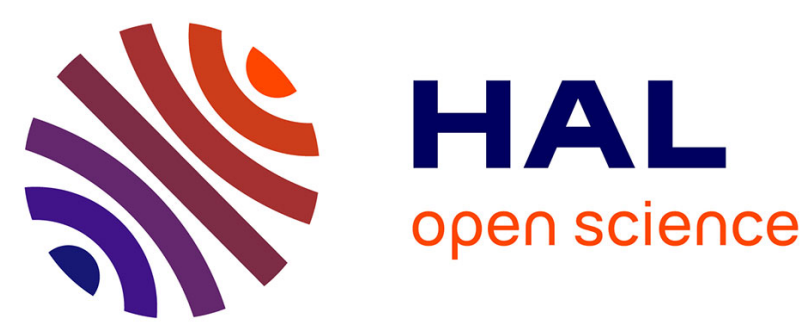

\title{
STRUCTURAL CHARACTERIZATION AND ELECTRICAL TRANSPORT PROPERTIES OF METAL MOLTEN SALT MIXTURES IN THE METALLIC CONDUCTIVITY REGIME
}

\author{
J. Dupuy, L. Hily, J.-F. Jal, P. Chieux, J. Gaspard
}

\section{To cite this version:}

J. Dupuy, L. Hily, J.-F. Jal, P. Chieux, J. Gaspard. STRUCTURAL CHARACTERIZATION AND ELECTRICAL TRANSPORT PROPERTIES OF METAL MOLTEN SALT MIXTURES IN THE METALLIC CONDUCTIVITY REGIME. Journal de Physique IV Proceedings, 1991, 01 (C5), pp.C531-C5-38. 10.1051/jp4:1991503 . jpa-00250627

\section{HAL Id: jpa-00250627 https://hal.science/jpa-00250627}

Submitted on 1 Jan 1991

HAL is a multi-disciplinary open access archive for the deposit and dissemination of scientific research documents, whether they are published or not. The documents may come from teaching and research institutions in France or abroad, or from public or private research centers.
L'archive ouverte pluridisciplinaire HAL, est destinée au dépôt et à la diffusion de documents scientifiques de niveau recherche, publiés ou non, émanant des établissements d'enseignement et de recherche français ou étrangers, des laboratoires publics ou privés. 


\title{
STRUCTURAL CHARACTERIZATION AND ELECTRICAL TRANSPORT PROPERTIES OF METAL MOLTEN SALT MIXTURES IN THE METALLIC CONDUCTIVITY REGIME
}

\author{
J. DUPUY, L. HILY, J.-F. JAL, P. CHIEUX* and J.R. GASPARD** \\ Département de Physique des Matériaux, Université Claude Bernard, F-69621 Lyon Villeurbanne, \\ France \\ *Institut Laue-Langevin, rue des Martyrs, F-38042 Grenoble, France \\ **Aluminium Pechiney, LRF, St Jean de Maurienne, France
}

\begin{abstract}
The microscopic structure of the mixture $\mathrm{K}_{\mathrm{X}}(\mathrm{KCl})_{1-\mathrm{x}}$ in the metallic regime ( $x=0.8$ and 0.9 ) has been investigated by neutron diffraction with the isotopic substitution technique. New measurements on the electrical transport properties are presented. For $\mathrm{x}=0.9$, the dominant metallic behavior is well established by the metalmetal correlations and the conductivity data. For $x=0.8$, there is evidence of stable ionic clustering. Concentration fluctuations are always important. The non homogeneous distribution of the chlorine atoms is emphasized.
\end{abstract}

The challenge of metal-molten salt solutions, which are structurally speaking, a rather simple system composed of only two types of ions, is to understand the correlations between the behavior of the electrons and that of the established ionic arrangements. In the metallic regime, we expect the chemical short range order and the long distance interactions due to ionic charges, to be considerably affected by electron screening. At concentrations between 20 and $60 \%$ of metal, where electrical conductivity is in a strong scattering regime, the proximity of a liquid-liquid critical point forces us to investigate not only the local order but also the structural inhomogeneities at medium distances. If 
fluctuations are detected at the mesoscopic level $(10<r(A)<300)$ they will have to be included in the picture of the electronic diffusion or localization process.

In this paper, we discuss results on the electrical transport properties and present new information on the structure of $\mathrm{K}_{\mathrm{x}} \mathrm{KCl}_{1-\mathrm{x}}$, with $\mathrm{x}>0.7$, i-e at concentrations which are typically metallic. We give in figure 1 , the phase diagram of $\mathrm{K} \mathrm{KCl}$ as well as some estimated iso- $\xi$ lines ( $\xi$ being the correlation length for the concentration fluctuations ). Small angle neutron scattering measurements performed on $\mathrm{K}-\mathrm{KBr}$ solutions (1) have given us a direct access to the iso- $\xi$ lines at concentrations between 30 and 55\% of metal. Further away from the critical conditions, when $\xi$ becomes small, one would like to rely on thermodynamic data (2).

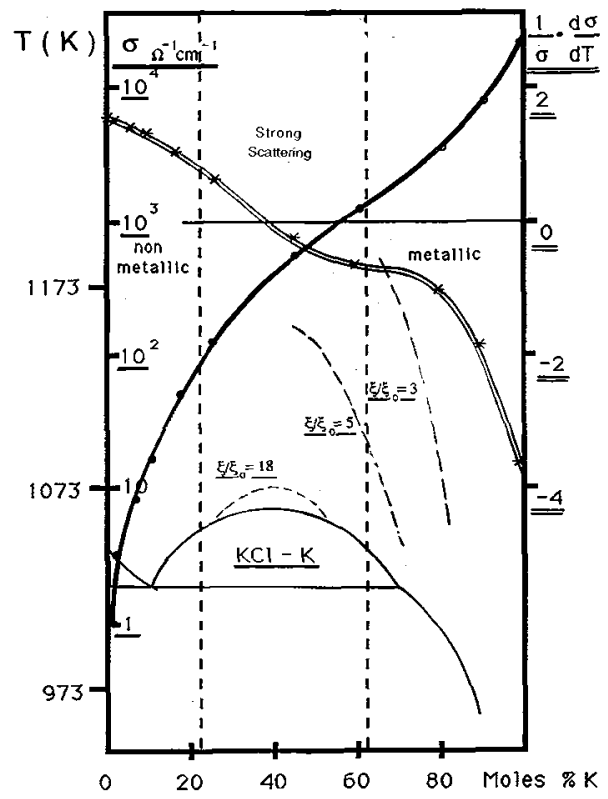

Figure 1 : Phase diagram with iso $\xi$-lines, electrical conductivity and its temperature derivative (6) (see text) for $\mathrm{K}-\mathrm{KCl}$

Since chemical potential measurements have been performed only in salt-rich solutions (3) or lack the requested accuracy (4), we have estimated the small reduced correlations lengths $\left(\xi / \xi_{0}=5\right.$ and 3 ) in the metallic regime ( see figure 1 ) with the help of the known scaling relation $\xi=\xi_{0} t^{-v}$, (where $t=\left(T-T_{C}\right) / T_{C}$ and with $\xi_{0}=1.6 \AA, v=0.63$ as in $\left.\mathrm{K}-\mathrm{KBr}\right)$ and the shape of the coexistence curve. This method is an extension to critical regime of the simple relation found between coexistence line, spinodal line and iso- $\xi$ lines for binary systems described by a mean field equation of state (5).

In view of the above phase diagram, several methods can be chosen to represent the electrical conductivity $\sigma$ or its temperature derivative, across the whole concentration range from salt to metal. The representation along isotherms cuts the iso- $\xi$ lines and emphasizes the perturbation due to critical fluctuations. A way to avoid this perturbation is to plot the conductivity measured at points along an iso- $\xi$ line, in other 
words, measured at a constant relative temperature with respect to the spinodal line ( ( $T$ $\left.T_{S}\right) / T_{S}=$ Cte $)$. This representation has been chosen for $1 / \sigma . d \sigma / d t$ in figure 1 , but it becomes rather inaccurate at concentrations away from critical where the iso- $\xi$ lines are illdefined. Another possibility is to display the conductivity measured at temperatures such as the system is always in equivalent thermodynamic states, which is achieved by working at the same reduced density with respect to melting point density. This allows us to follow the effects of compositional change decoupled from changes in the structural or topological short range order. This choice has been made for the electrical conductivity given in figure 1 which was measured at temperatures such as $\rho / \rho_{m} . p=0.95$. Of course, in the vicinity of the critical point, we encounter the same probems as when following the isotherms. However, whatever is the representation, the conductivity results (6) are well in the metallic regime for $x>0.7$ but show signs of departure from the typical dense plasma behavior of pure Potassium for more than $10 \%$ of salt addition $(x<0.9)$. It is therefore interesting to compare in detail two metallic solutions ( $x=0.9$ and $x=0.8$ ) which might reveal structural differences.

The total structure factors, $S(k)$, of the $x=0.8$ and 0.9 solutions have been obtained from neutron diffraction on the D4b spectrometer (ILL, Grenoble) for three chlorine isotopic compositions ( $99 \%{ }^{35} \mathrm{Cl}, 65 \%{ }^{35} \mathrm{Cl}$ or natural composition, $8 \%{ }^{35} \mathrm{Cl}$ ), respectively called ${ }^{35} \mathrm{Cl}$, nat $\mathrm{Cl},{ }^{37} \mathrm{Cl}$. The results are displayed in Figure 2. The most striking feature is (except for the ${ }^{37} \mathrm{Cl}$ samples), the weakness of the signal, since $S(\mathrm{k})$ culminates at about 1.1 only. The lower the $k$ value ( $k$ is the momentum transfer ), the larger the difference brought about by isotopic substitution. A point of interest is the strength of the small angle signal, which surprisingly remains significant even at $x=0.9$, i-e far from $x_{c}=0.4$. The estimates of $\xi / \xi_{0}$ based on near critical values and extrapolated to the $x=0.9$ concentration seem to be confirmed, although a quantitative agreement remains to be proved. The observed difference in the low $k$ behavior of the various isotopes implies some constraints at $k=0$, such as a positive value for $S_{c c}(0)$, the thermodynamic limit related to concentration fluctuations, and a positive value for the volume effect $\delta$, ( where $\left.\delta=(\mathrm{N} / \mathrm{V})\left(\mathrm{V}_{\mathrm{K}}-\mathrm{V}_{\mathrm{KCl}}\right)\right)$. These constraints are in qualitative agreement with measurements of excess volume (7) and will be compared with chemical potential results as soon as available (2).

From the total structure factors, it is possible to extract the Faber-Ziman partial structure factors describing the like and unlike atomic pair distributions. The comparison between the $S_{\mathrm{KCl}}$ partials of a purely ionic network such as $\mathrm{KCl}$ and those of the $x=0.8$ 


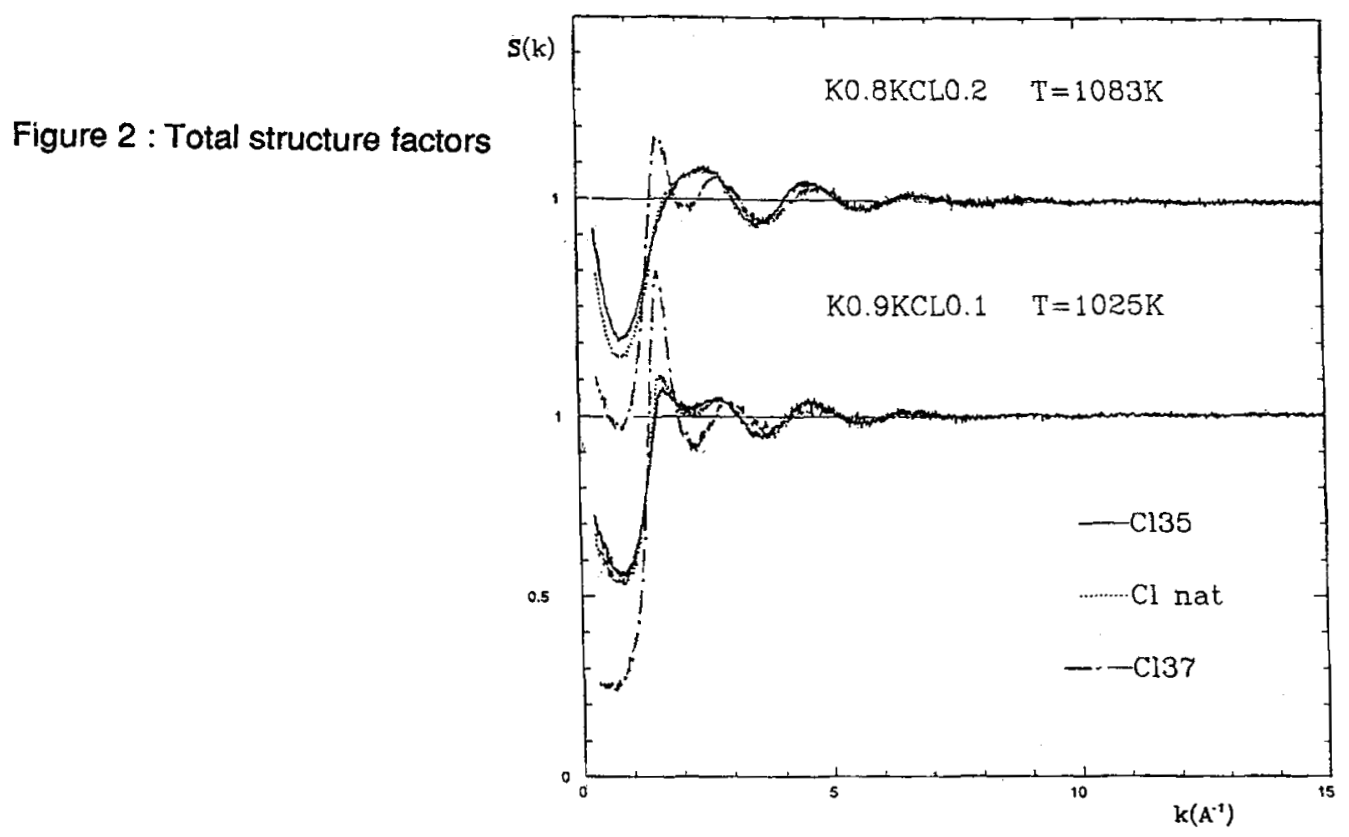

Figure 3 : $S_{\mathrm{KCl}}(x=0.9,0.8,0$. and Fourier transforms (insert)

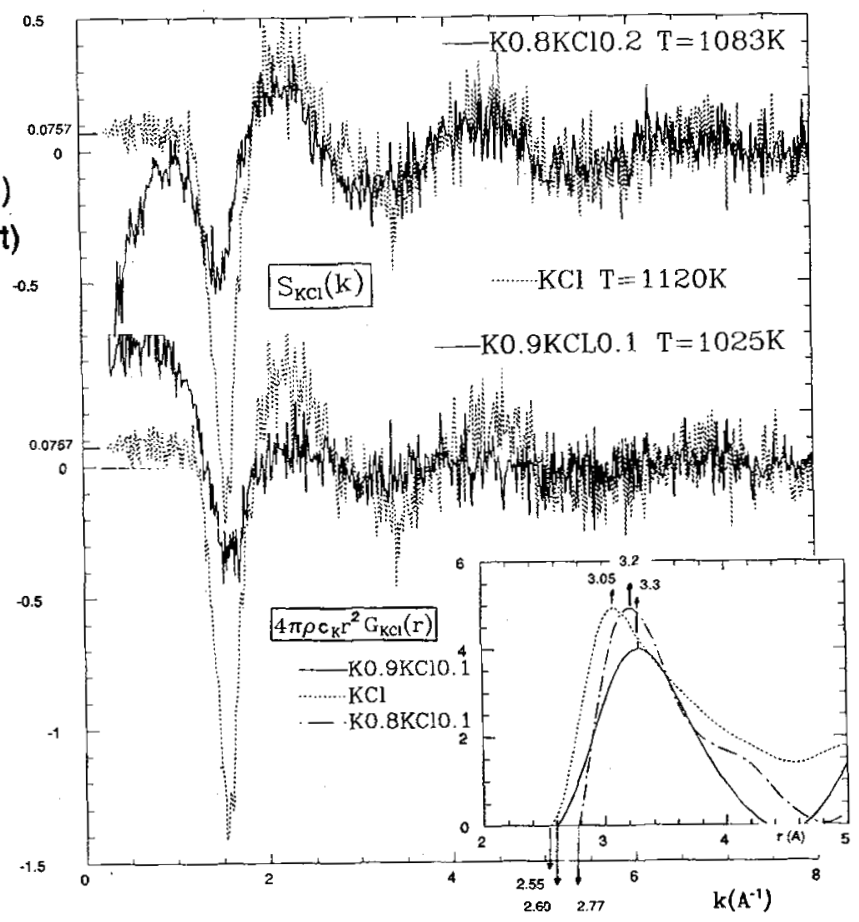


and 0.9 solutions ( see Figure 3 ) shows that the main differences occur at low $k$ values, and concern especially the depth of the first minimum, which is related to the real space extent of the alternance of unlike atoms. As far as the local order is concerned, the heteroatomic distribution seems to be unquestionably maintained at metallic concentrations. A study of the first shell of unlike atoms given by the unlike partial radial distribution function ( see insert of Figure 3 ) is instructive in this respect. Pure $\mathrm{KCl}$ has a first shell which is open to interactions with higher order shells and containing 6 unlike atom neighbors. The $x=0.8$ solution on the other hand, has a close first shell containing 4 unlike atom neighbors and we observe a significant shift $(\sim 0.20 \AA)$ of this shell towards larger distances. (Systematic errors in $G(r)$ due to data analysis and Fourier transform have been investigated. Their effect on the first unlike neighbor shell located at relatively large $r$ values, is minor $(<10 \%)$, furthermore for each concentration, they affect the shell position, area and cutoff in a similar manner ). For $x=0.9$, the well defined first shell contains only 3 atoms. Therefore, the ionic network structure has been lost, and there is evidence for ionic clustering at metallic concentrations. A model description for this clustering and its coordination symmetry should be developed.

The metal-metal partial structure factor for $x=0.9$, is displayed in Figure $4 a$ with the pure metal structure factor taken at the same reduced density $\left(\rho / \rho_{\text {m.p. }}=0.95\right)$. Except for the main peak height, $S\left(k_{1}\right)$ and for a small systematic error in the low $k$ values for $x=0.9$, the similarity is striking. To compare more quantitatively to two structures, we plot in the insert of figure $4 a$, the dependence of the pure metal main peak height versus reduced density, which shows that for $\rho>0.8 \rho$ m.p. the one component plasma model description of the structure is obeyed (8). In the same insert, for the $x=0.9$ solution, the main peak height of $S_{K K}$ lies on a lower line with intensity values similar to a metal in the reduced density range $0.80<\rho / \rho_{m}$. p. $<0.85$, a shift of intensities corresponding to a $15 \%$ expansion of the metal. Dilution to the $x=0.8$ concentration, always at $\rho / \rho_{m} . p .=0.95$, does not further modify the main peak height of $S_{K K}$, as seen in figure $4 \mathrm{~b}$. However, we then observe a strong low angle signal due to the approach of the critical conditions and an enhancement of the oscillations after the main peak. These features are not predictable by simple models of the $M-M X$ solutions (8). From the $S_{K K}$ partials it seems therefore that for $x=0.9$, the solutions properties should be treated as in expanded metals, but for $x=$ 0.8 , new structural arrangements due to concentration fluctuations and to more repulsive $\mathrm{K}-\mathrm{K}$ interactions ( see Figure $4 b$, insert) are perturbing the expanded metal picture. 


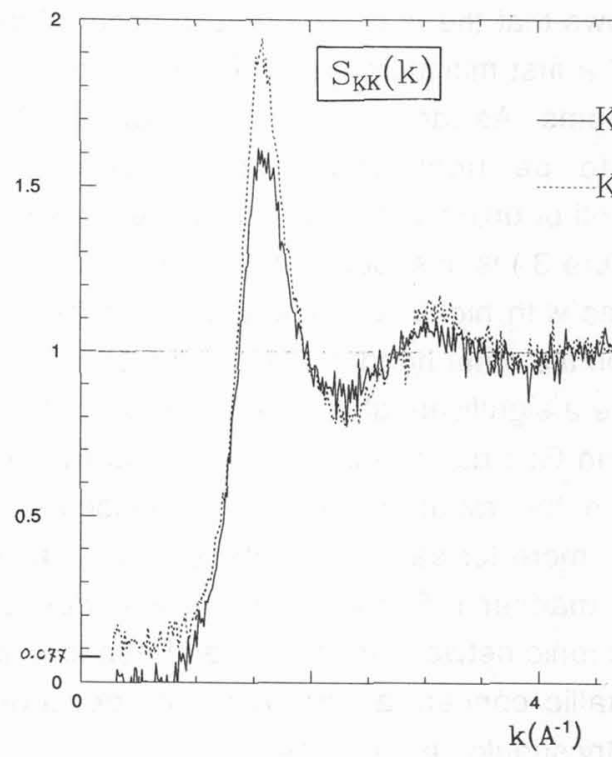

Figure $4 a$ : $S_{K K}$ for $x=0.9$,

$\mathrm{S}\left(\mathrm{k}_{1}\right)$ for alkali metals (insert)

K0.9KCl0.1 T=1025K

$\mathrm{K}$ pur $\mathrm{T}=773 \mathrm{~K}$

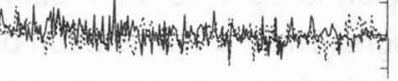
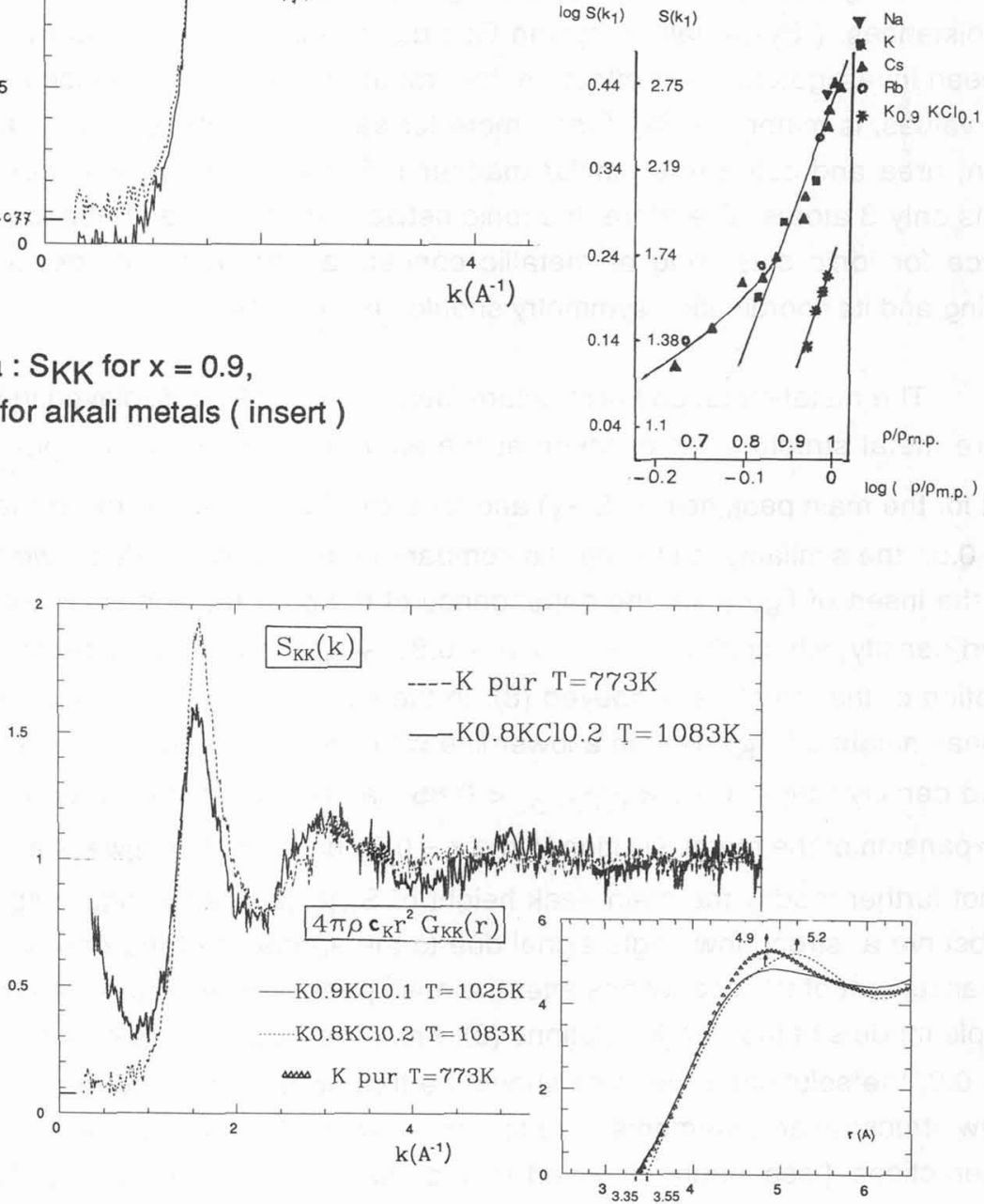

Figure $4 b: S_{K K}$ for $x=0.8$

Fourier transforms $(x=1,0.9,0.8)$ 
Finally, we display the chlorine-chlorine partial structure factor in Figure 5. For $x=0.8$ the correlations between the like ions structures are established, but the first peak of $\mathrm{S}_{\mathrm{ClCl}}$ is very weak, pointing to the non existence of long range order of the chlorine atoms. For $x=0.9$, the breakdown of the $S_{\mathrm{ClCl}}$ structure is spectacular, the first peak has disappeared and the signal in the $1.5<\mathrm{k}<3 \AA^{-1}$ range is nearly structureless and very different from the one of $S_{K K}$. The low $k$ behavior of the chlorine partials is also interesting as, at both concentrations, it is 2 or 3 times superior to the $S_{K K}$ low angle scattering, implying strong fluctuations in the distribution of the chlorine atoms $i-e$ local heterogeneity in the structure. Indeed, it is worthwhile to note (9) that in going from $x=0.6$ to 0.8 , there is not much change in the first neighbors of the chlorine atoms distribution (see insert of Figure 5 ), although the chlorine concentration is significantly reduced. It would be interesting to follow this trend up to $x=0.9$, but the Fourier Transform of the structureless $S_{\mathrm{CICl}}$ partial is too uncertain to be discussed. In any case, with increasing metal content, there seems to be a tendency for the chlorine atoms to regroup in order to retain as much as possible the local order they have in solutions richer in salt.

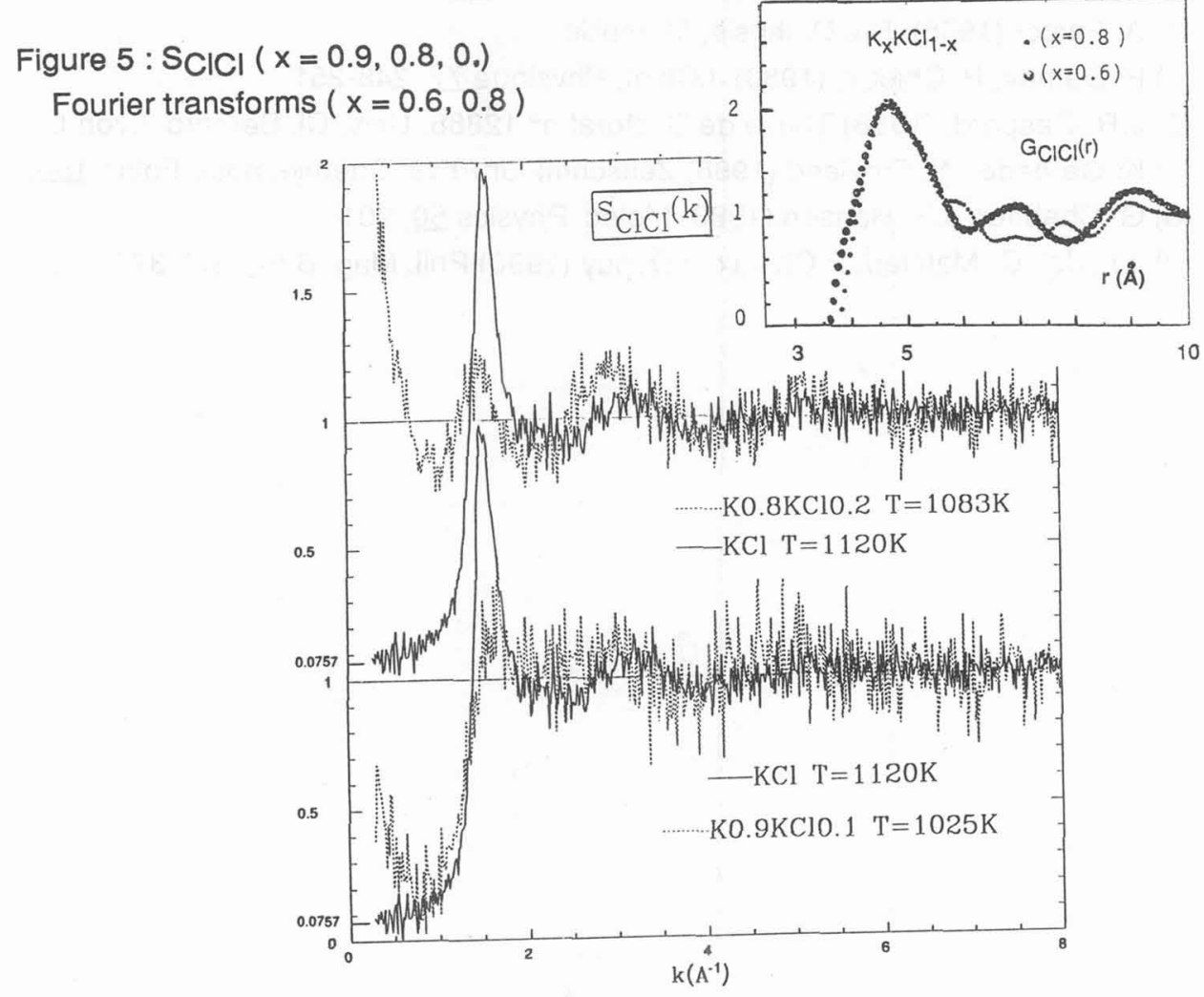


This brief description of the main structural characteristics of the $x=0.8$ and $x=$ $0.9 \mathrm{~K}_{\mathrm{x}} \mathrm{KCl}_{1-\mathrm{x}}$ solutions points to a rather distinct behavior. In both cases, the potassium distribution can be described as an expanded metal, although at $x=0.8$ some perturbations are detected, but it is the chlorine distribution which is of key importance. The chlorine ions are not homogeneously spread in the system but tend to aggregate with the potassium ions which is somewhat unstable and ill-defined for $x=0.9$ but seems to be $a$ characteristic ionic clustering for $x=0.8$. Concentration fluctuations commanded by the liquid-liquid critical point, modulate this local order description. The electronic transport properties which we have introduced in figure 1 , remain to be described at this microscopic level and in particular, one should study the effect of the distribution of chlorine atoms on the electron gas and for more dilute solutions of ionic clustering on the electron localization process.

\section{References}

(1) J.F. Jal, P.Chieux, J.Dupuy, J.P. Dupin (1980) J. de Physique 41, 657-666

(2) experiment in progress, in collaboration with R. Schmutzler

(3) M.V. Smirnov et al, (1981) Electrochim. Acta, 26, 1275

(4) A. Farcot (1985), Ph. D. thesis, Marseille

(5) P. Damay, P. Chieux, (1980) J.Chim. Physique 77, 248-251

(6) J.R. Gaspard, (1988) Thèse de Doctorat $n^{\circ} 12888$. Univ. Cl. Bernard, Lyon I.

(7) K. Garbade, W. Freyland (1988) Zeitschrift fur Phys. Chemie, neue Folge 156, 169-175

(8) G. Chabrier, J.P. Hansen (1983) Molec. Physics 50, 901

(9) J.F. Jal, C. Mathieu, P.Chieux, J.Dupuy (1990) Phil. Mag. B 62, 351-372 